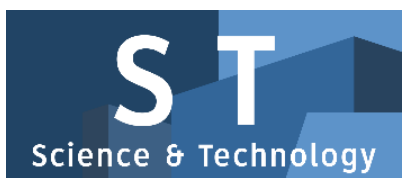

PAPER - OPEN ACCESS

\title{
Analisis Numerik Evaporator Pada Desalinasi Surya Sistem Vakum Alami
}

\author{
Author : Agistya D. Ronowikarto \\ DOI $\quad: 10.32734 /$ st.v1i2.288 \\ Electronic ISSN : :2654-7082 \\ Print ISSN $\quad:$ 2654-7074
}

Volume 1 Issue 2 - 2018 TALENTA Conference Series: Science \& Technology (ST)

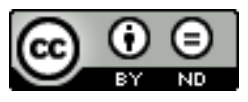

This work is licensed under a Creative Commons Attribution-NoDerivatives 4.0 International License.

Published under licence by TALENTA Publisher, Universitas Sumatera Utara
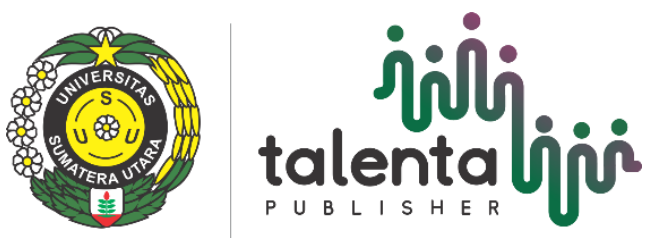


\title{
Analisis Numerik Evaporator Pada Desalinasi Surya Sistem Vakum Alami
}

\author{
Agistya D. Ronowikarto ${ }^{\mathrm{a}, b^{*}}$, Ridho Elranda T. Siregar ${ }^{\mathrm{a}, \mathrm{b}}$, Himsar Ambarita ${ }^{\mathrm{a}, \mathrm{b}}$ \\ ${ }^{a}$ Departemen Teknik Mesin, Fakultas Teknik, Universitas Sumatera Utara, Medan, Indonesia \\ ${ }^{b}$ Pusat Riset Energi Berkelanjutan, Teknik Mesin, Universitas Sumatera Utara, Medan, Indonesia
}

agistyad@gmail.com

\begin{abstract}
Abstrak
Teknologi desalinasi merupakan salah satu solusi dari kelangkaan air bersih yang terjadi. Dengan menggunakan energi terbarukan yang digunakan oleh proses desalinasi umumnya berupa energi surya, angin, dan geotermal diharapkan dapat mengurangi kebutuhan energi dalam sistem desalinasi. Pada penelitian ini telah dilakukan analisis numerik perpindahan fraksi volume massa dan laju penguapan yang terjadi pada evaporator. Analisis numerik diasumsikan sebagai kasus 3 dimensi. Persamaan pembentukan fluida didiskritasikan menjadi suatu persamaan menggunakan metode volume hingga. Pada hasil simulasi dapat dilihat bahwa terjadi proses evaporasi-kondensasi pada evaporator berdasarkan hasil kontur volume fraksi dan laju penguapan berdasarkan hasil simulasi adalah sebesar $4,36 \times \square 10 \rrbracket \wedge(-5)$ dengan hasil produktifitas air bersih sebanyak 1,3 liter. Hasil simulasi akan dibandingkan dengan hasil eksperimental. Dengan hasil perhitungan matematis, produktifitas air bersih sebanyak 1,38 liter akan dibandingkan dengan hasil simulasi, maka didapat bahwa terdapat ralat sebesar 6,1\%.Hal ini menunjukkan bahwa evaporator pada teknologi desalinasi surya sistem vakum alami telah bekerja dengan baik.
\end{abstract}

\section{Pendahuluan}

United Nations Organization sudah memperkirakan bahwa pada tahun 2025, hampir 1800 juta jiwa di dunia akan mengalami kelangkaan air bersih (UN-Water)[1]. Untuk mengatasi hal ini perlu dicari solusi yang dapat dilakukan. Salah satunya dengan membuat teknologi desalinasi. Teknologi desalinasi telah dikembangkan sejak lama menyerupai siklus hidrologi alami untuk mencegah permasalahan ini, tetapi teknologi ini tentunya memerlukan energi yang banyak.Dengan menggunakan energi terbarukan yang digunakan oleh proses desalinasi umumnya berupa energi surya, angin, dan geothermal diharapkan dapat mengurangi kebutuhan energi dalam sistem desalinasi. Menurut Eltawil, dkk [1], di antara ketiganya, 57\% sistem desalinasi disuplai dengan tenaga surya sebagai energi terbarukan.

Desalinasi pada prinsipnya merupakan cara untuk mendapatkan air bersih melalui proses penyulingan air kotor. Secara umum terdapat berbagai cara yang sering digunakan untuk mendapatkan air bersih yaitu : perebusan, penyaringan, desalinasi dan lain-lainnya. Cara perebusan dilakukan hanya untuk mematikan kuman dan bakteri-bakteri yang merugikan, namun kotoran yang berupa padatan- padatan kecil tidak bisa terpisah dengan air[4].

Penyaringan digunakan hanya untuk menyaring kotoran-kotoran yang berupa padatan kecil, namun kuman dan bakteri yang merugikan tidak bisa terpisah dari air. Cara desalinasi merupakan cara yang efektif digunakan untuk menghasilkan air bersih yang bebas dari kuman, bakteri, dan kotoran yang berupa padatan kecil. Menurut Ketut, dkk 
[2] proses desalinasi secara umum biasanya yang diambil hanyalah air kondensatnya, sedangkan konsentrat garam dibuang dan ini dapat berakibat buruk bagi kehidupan air laut.

Prinsip kerja desalinasi secara umum sebenarnya sangat sederhana. Air laut dipanaskan hingga menguap, dan kemudian uap yang dihasilkan dikondensasikan kembali dan ditampung di sebuah wadah. Air kondensat tersebut adalah air bersih. Sedangkan air laut yang tidak mendidih selama pemanasan adalah konsentrat garam. Pemanas dalam desalinasi surya sistem vakum alami adalah pipa tembaga berisi fluida yang dipanaskan dengan menggunakan kolektor surya. Evaporator sebagai media pemanas evaporator merupakan komponen penting dalam desalinasi. Analisis numerik dengan menggunakan Computational Fluid Dynamics telah dilakukan untuk menentukan desain evaporator yang tepat. Analisis numerik ini dilakukan untuk mengetahui laju penguapan yang terjadi. Hasil numerik akan dibandingkan dengan hasil perhitungan.

\section{Bahan dan Metode}

\subsection{Lokasi penelitian}

Lokasi penelitian dilakukan di Pusat Riset Energi Berkelanjutan, Magister Teknik Mesin, Universitas Sumatera Utara, kota Medan dengan lokasi geografis $3^{\circ} 30^{\prime}-3^{\circ} 43^{\prime}$ Lintang Utara dan $98^{\circ} 35^{\prime}-98^{\circ} 44^{\prime}$ Bujur Timur.

\subsection{Metode}

Penelitian ini dilakukan selama 6 bulan, dimulai pada bulan Februari sampai Agustus 2017. Evaporator dengan bahan stainless-steel merupakan media pemanas air laut pada desalinasi surya sistem vakum alami. Kolektor surya digunakan untuk memanaskan fluida di dalam pipa pemanas berbahan tembaga. Fluida yang telah dipanaskan dalam pipa tembaga akan mengalir ke dalam pipa di dalam evaporator. Fotovoltaik sebagai penggerak pompa untuk sirkulasi di dalam pipa tembaga kolektor surya dan evaporator. Pembentukan sistem vakum bertujuan untuk menurunkan tekanan ruang evaporator agar pemanasan dapat berlangsung dengan suplai panas yang rendah ${ }^{[4]}$. Tekanan atmosfer pada evaporator akan sama dengan tekanan hidrostatis yang disebabkan oleh air pada pipa yang tingginya sekitar 10,34 meter. Dengan ketinggian pipa lebih dari 10,34 meter dan ditutup dari bagian atas dengan air, dan air dibiarkan jatuh ke bawah akibat gravitasi, air akan jatuh pada ketinggian sekitar 10,34 meter, dan membentuk ruang vakum di atasnya [4]. Desalinasi surya sistem vakum alami yang telah dibuat dapat dilihat pada Gambar 1(a). Domainuntuk analisis dibuat pada gambar 3 dimensi menggunakan perangkat lunak CAD, SolidWorks 2016. Penelitian difokuskan untuk mengetahui fraksi volume massa dan laju penguapan pada evaporator.

\subsection{Metode Numerik}

Pada penelitian ini, akan dianalisis fraksi volume massa dan laju penguapan yang terjadi pada evaporator. Domain analisis numerik dapat dilihat pada Gambar 1(b). Domain analisis numerik didesain menggunakan perangkat lunak SolidWorks 2016. Evaporator dengan dimensi diameter sebesar $80 \mathrm{~cm}$ digunakan pada analisis numerik. Analisis numerik dengan kasus 3-dimensi telah dilakukan. 


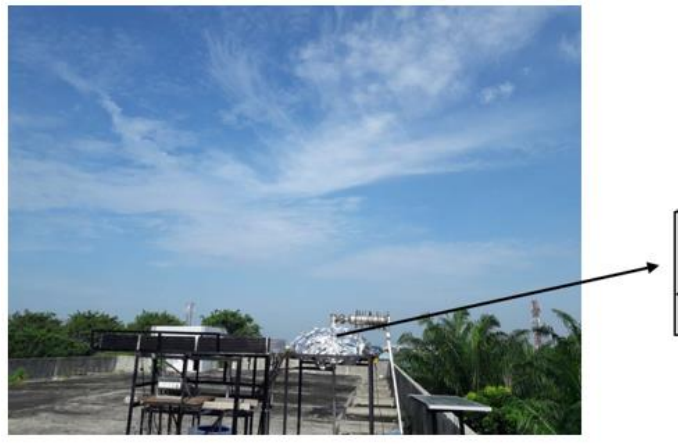

(a) Desalinasi Surya Sistem Vakum Alami

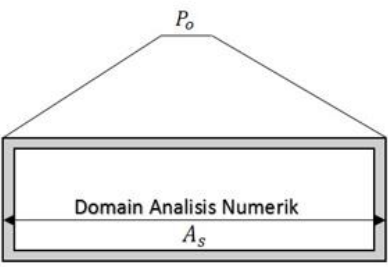

(b) Model untuk Analisis Numerik

Gambar 1. Foto desalinasi surya sistem vakum alami dan model untuk analisis numerik

Pada analisis, domain dianggap kasus 3 dimensi. Aliran pada analisis diasumsikan sebagai $k$-epsilon dan transient. Asumsi tambahan adalah tekanan sistem merupakan tekanan vakum senilai 0,46 atm ,tekanan gas dan cair sama, dengan temperatur pipa pemanas pada pukul $13: 00$ yaitu $68^{\circ} \mathrm{C}$ (didapat berdasarkan hasil pegujian, Gambar 2.), gaya gravitasi pada arah garis $y$, semua sifat termofisik fluida dianggap konstan dan tidak terjadi perpindahan panas keluar evaporator (fluks panas $=0$ ).

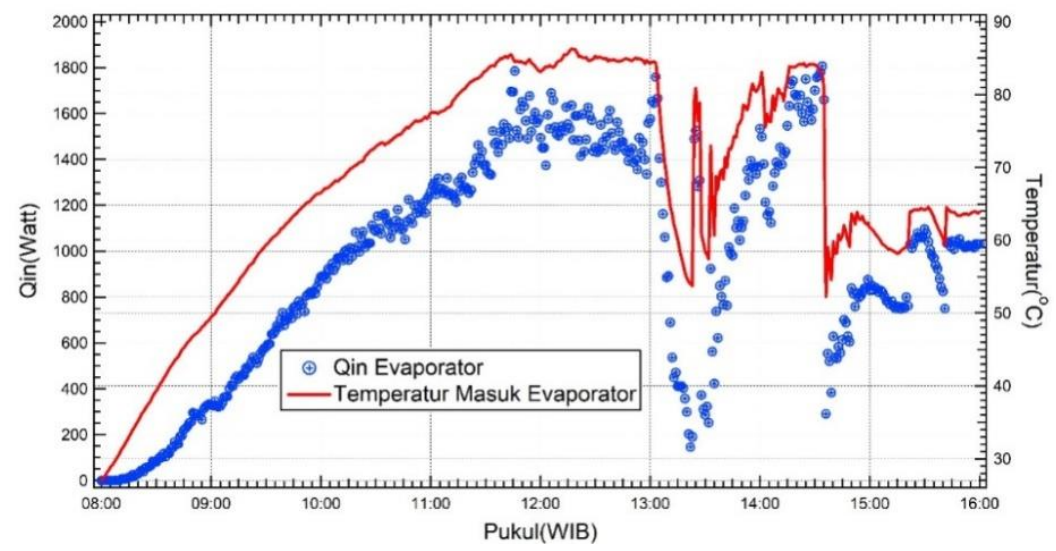

Gambar 2. Grafik Perbandingan Qmasuk Evaporator dan Tmasuk Evaporator

\subsubsection{Parameter tekanan [3]}

- Tekanan

$$
P_{G}=P_{L}=P
$$

1.

1. Persamaan perpindahan fraksi massa

Persamaan laju perpindahan fraksi massa dalam evaporator dapat dirumuskan menjadi [3]:

- $\quad$ Fasa Gas

$$
\nabla \cdot\left[r_{G}\left(\rho_{G} V_{G} Y_{A}-\rho_{G} D_{A G}\left(\nabla Y_{A}\right)\right)\right]-S_{L G}=0
$$


- $\quad$ Fasa Cair

$$
\nabla \cdot\left[r_{L}\left(\rho_{L} V_{L} Y_{A}-\rho_{L} D_{A L}\left(\nabla X_{A}\right)\right)\right]+S_{L G}=0
$$

- Laju penguapan (evaporasi) dari air laut di dalam evaporator (dinyatakan dengan huruf " $s$ ") ke dalam air murni di kondensor (dinyatakan dengan huruf ' $f$ ') dapat dirumuskan dengan menggunakan persamaan berikut [4]:

$$
\dot{V}_{e}=A_{\text {surface }} \frac{\alpha_{m}}{\rho_{f}}\left|f\left(C_{S}\right) \frac{P\left(T_{s}\right)}{\left(T_{S}+273\right)^{0,5}}-\frac{P\left(T_{f}\right)}{\left(T_{f}+273\right)^{0,5}}\right|
$$

- $\quad$ Di mana $A_{\text {sufface }}$ adalah luas permukaan air yang ada di evaporator [4]:

$$
A_{\text {surface }}=\frac{1}{4} \pi d^{2}
$$

- $\quad$ Di mana parameter koefisien empirik adalah [4]:

$$
\alpha_{m}=10^{-7} \mathrm{~kg} / \mathrm{m}^{2} . \text { Pa.s. } K^{0,5}
$$

- Tekanan uap dengan fungsi temperatur dapat dirumuskan dengan persamaan [5]

$$
P(T)=100 \times e^{\left[63,042-\frac{7139,6}{(T+273)}-6,2558 \ln (T+273)\right]}
$$

- $\quad f(C)$ adalah faktor koreksi yang dihitung dengan menggunakan persamaan [5]:

$$
f(C)=1-\alpha_{1} C
$$

Di mana $\alpha_{1}=0,0054$ [tanpa dimensi] adalah koefisien empirik. [5]

- Untuk mengetahui total evaporasi pada evaporator, maka digunakan persamaan berikut [6]:

$$
m=\dot{m} \times t(9)
$$

- Dan untuk mengetahui hasil air bersih hasil kondensasi pada evaporator, adalah sebagai berikut [6]:

$$
V=\frac{m}{\rho}(10)
$$

Semua persamaan akan disubtitusikan ke dalam satu persamaan dengan menggunakan metode volume hingga. Persamaan tersebut akan diselesaikan dengan algoritma SIMPLE. Analisis numerik metode volume hingga menggunakan perangkat lunak ANSYS FLUENT. 


\section{Hasil}

\subsection{Karakteristik Fraksi Massa}

Gambar 3 (a) (b) menunjukkan karakteristik laju fraksi massa yang terjadi pada evaporator. Pada gambar dapat dilihat bahwa terjadi perbedaan fasa. Warna kuning menjukkan bahwa terdapat fasa gas pada evaporator dan warna biru merupakan fasa cair yang terjadi akibat adanya fenomena evaporasi-kondensasi. Fenomena ini terjadi pada tekanan vakum sebesar 0,46 atm.

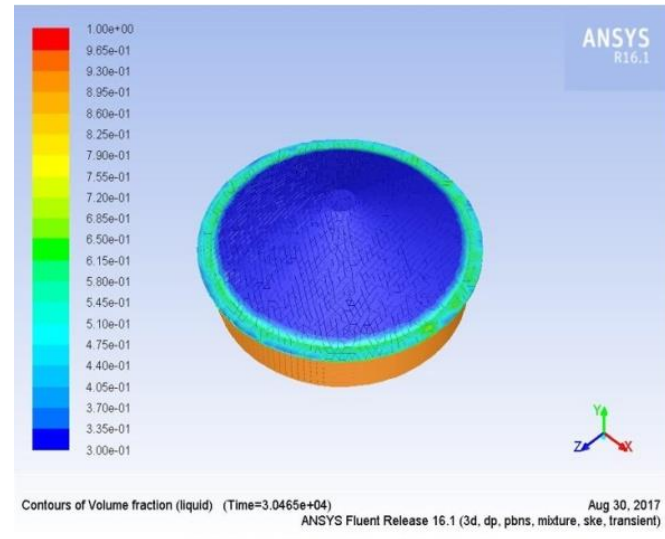

(a) Kontur Fraksi Massa (Tertutup)

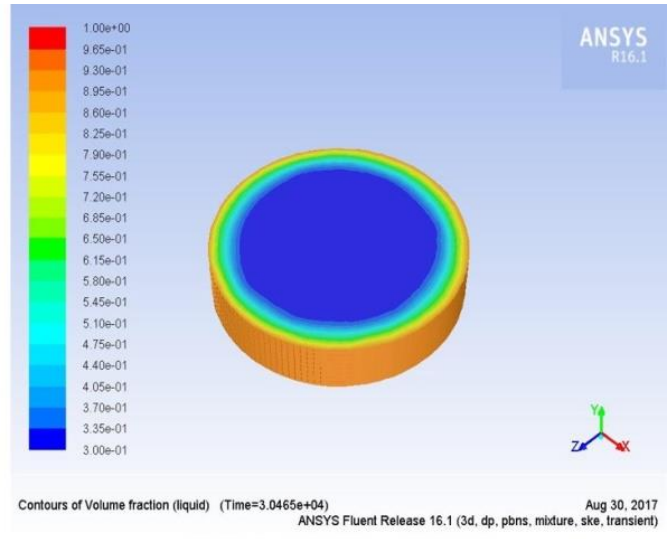

(b) Kontur Fraksi Massa (Terbuka)

Gambar 3. Kontur Fraksi Massa Pada Saat Tertutup dan Terbuka

\subsection{Laju Penguapan}

Penguapan yang terjadi akibat proses evaporasi-kondensasi pada evaporator dianalisis dengan metode volume hingga menggunakan ANSYS FLUENT. Nilai laju penguapan yang didapat berdasarkan analisis numerik yaitu sebesar $4,36 \times 10^{-5}$. Dengan mensubtitusikan angka tersebut ke dalam persamaan (9) dan (10) maka didapat hasil air bersih yaitu sebesar 1,3 liter. Dan dengan melakukan perhitungan matematis menggunakan persamaan (4) dan (7) didapat hasil air bersih sebesar 1,38 liter. Hal ini menunjukkan bahwa terjadi ralat sebesar 6,1\%.

\section{Pembahasan}

Berdasarkan analisis numerik yang telah dilakukan dapat diketahui bahwa terjadi fenomena evaporasi-kondensasi pada evaporator. Menurut Al-Kharabsheh [4], dengan kondisi tekanan operasi yaitu tekanan vakum akan menurunkan temperatur saturasi pada evaporator. Hal ini diharapkan akan menurunkan kebutuhan suplai panas. Pada penelitian ini, temperatur fluida dalam pipa pemanas yang digunakan untuk memanaskan air laut adalah sebesar $68^{\circ} \mathrm{C}$. Proses evaporasi mulai terjadi pada temperatur fluida mencapai $65^{\circ} \mathrm{C}$. Hal ini membuktikan bahwa terjadi penurunan temperatur saturasi dari air laut.

\section{Kesimpulan dan Saran}

Berdasarkan analisis numerik pada evaporator terjadi fenomena evaporasi-kondensasi dengan laju penguapan senilai 4,36× $10 \unlhd \wedge(-5)$. Hasil kondensasi dari air laut akan menjadi air bersih. Setelah dilakukan analisis numerik dan perhitungan matematis terhadap laju penguapan, maka didapat hasil air yaitu sebesar 1,3 liter dan 1,38 liter. Hal ini menyebabkan ralat sebesar 6,1\%.Untuk mengetahui apakah air hasil kondensat tersebut layak untuk diminum maka dilakukan pengujian laboratorium. Berdasarkan sifat termofisiknya dapat disimpulkan bahwa air tersebut layak untuk diminum. Untuk penelitian berikutnya diharapkan dapat menurunkan nilai tekanan vakum agar penurunan temperatur 
saturasi lebih tinggi. Serta pemasangan isolator pada evaporator diharapkan lebih baik lagi agar tidak terjadi perpindahan panas keluar evaporator (fluks panas diusahakan 0) agar air laut dapat terevaporasi dengan maksimal.

\subsection{Ucapan Terima Kasih}

Penelitian ini merupakan salah satu dari hasil Tugas Akhir Mahasiswa/I Teknik Mesin Angkatan 2013 yang bergabung dalam tim Desalinasi Surya pada Pusat Riset Energi Berkelanjutan. Penulis mengucapkan terima kasih kepada Dr. Eng. Himsar Ambarita, S.T, M.T selaku dosen pembimbing dan kepada rekan-rekan dalam tim Desalinasi Surya tahun 2017.

\section{Referensi}

[1] Eltawil, A., Zhengming, Z., Liqing, Y., 2008, Renewable Energy Powered Desalination Systems:Technologies And Economics-State Of The Art, Twelfth International Water TechnologyConference, Alexandria, Egypt, 22-23.

[2] Astawa, K., Sucipta, M., I Putu Gede A., 2011, Analisa Performansi Destilasi Air Laut Tenaga SuryaMenggunakan Penyerap Radiasi Surya Tipe Bergelombang Berbahan Dasar Beton, Jurnal Ilmiah Teknik Mesin Cakra M 5 (2011), 7-13.

[3] Setoodeh, N., Rahimi, R, Ameri, A., 2010, Modelling and determination of heat transfer coefficient in a basin solar still using CFD, Journal of Desalination 268 (2011), 103-110.

[4] Al-Kharabsheh, A and Goswani, D.Y., Theoretical analysis of a water desalination system using low grade solar heat, Journal of Solar Energy Engineering 126 (2004), 774-780.

[5] Rohsenow, W.M, Harnett, J.P, Ganic, E.N 1985 Handbook of Heat Transfer. New York: McGraw-Hill Book Company 